\title{
LXX. On the probable mode of constructing the pyramids; introduced by letters relating to the history of the subject, addressed to Lieut.-Col. Sabine, Lieut.-Col. Dansey, and the author
}

\author{
Henry Perigal Esq.
}

To cite this article: Henry Perigal Esq. (1844) LXX. On the probable mode of constructing the pyramids; introduced by letters relating to the history of the subject, addressed to Lieut.-Col. Sabine, Lieut.-Col. Dansey, and the author , Philosophical Magazine Series 3, 25:168, 404-412, DOI: $10.1080 / 14786444408646078$

To link to this article: http://dx.doi.org/10.1080/14786444408646078

\section{Published online: 30 Apr 2009.}

Submit your article to this journal $₫$

\section{Llll Article views: 4}

Q View related articles $\sqsubset$ 


\section{Mr. Perigal on the Mode of Constructing the Pyramids.}

express $p$, would be sufficient to exclude $p$ from a claim upon the exponent for its general logarithm.

Mr. Graves says (Phil. Mag. S. 3. vol.viii. p. 281) "I call $\frac{1}{2}$ an $e-\log$ of $-\sqrt{e}$ as well as of $+\sqrt{ } \bar{e} . "$ But this departure from the usual doctrine is not essential to the stability of Mr. Graves's system; and I submit that if, to subserve ulterior purposes, $+\sqrt{ } e$ be fixed upon, $-\sqrt{ } e$ is at once deprived of its claim, the ambiguity remaining only till the selection is made; both cannot claim this designation, but only one or the other, just as in the case of + and - in the theory of coordinates.

These few observations may perhaps contribute to revive attention to $\mathrm{Mr}$. Graves's interesting and masterly researches into the general theory of exponentials; and they may possibly help to show that the system of imaginary logarithms which he has established, is established upon precisely the same basis as that which was required to support the older imperfect doctrine, without the aid of any new principle or postulate.

Belfast, November 12, 1844.

LXX. On the Probable Mode of Constructing the Pyramids; introduced by Letters relating to the History of the subject, addressed to Lient.-Col. Sabine, Lieut.-Col. Dansey, and the Author. By Henry Perigal, Esq.*

To Lieut.-Colonel Sabine, F.R.S., \&c., General Secretary of the British Association for the Advancement of Science, York.

Sir,

T $\mathrm{N}$ offering for communication to the British Association 1 for the Advancement of Science the accompanying description of a (supposed Egyptian) mode of raising very large stones, I take leave to annex copies of two letters, which explain that my discovery of this method of raising heavy weights had been anticipated by Lieut.-Col. Dansey, of the Royal Artillery; and to add that, in an interview I sought with him, I found that our plans were almost identical, and learned the gratifying fact that in 1834, when the Egyptian antiquities at the British Museum were transferred to the new gallery, under the personal direction of Col. Dansey, this method was partially adopted in the removal of "Young Memnon." Consequently no doubt need be entertained of its being practicable. The question for discussion, therefore, is whether such a plan was actually practised by the Egyptians in constructing the Pyramids, \&c. I am, Sir, yours truly, Snith Street, Chelsea, Sept. 24, 1844.

\section{Hentry Perigal.}

* Commuricated by the Author; having been read before the Section of Mechanical Science of the British Association, at the (second) meeting at York, September 27, 1844. 
To Lieut.-Col. Dansey, Woolwich.

SrR, - I called upon Dr. Faraday yesterday, to beg him to take charge of a paper I wished to present to the British Association for the Advancement of Science, on a mode of raising very ponderous stones, practised, as I imagine, by the Egyptians in the erection of their pyramids and temples; by the Druids in constructing Stonehenge; and in the location of rocking-stones, \&c.; which I had re-invented in the month of May last. On seeing the explanatory diagrams I have had engraved, he told me he had some recollection that a plan on a similar principle (viz. by tilting the stone) was proposed by you, many years ago, for lifting heavy guns, \&c.; and he recommended me to write to you about it.

Of course, under these circumstances, I feel constrained to pause, lest I should risk the imputation of plagiarism; I trust therefore you will kindly furnish me with the requisite information as to whether your contrivance had reference to the construction of the Pyramids, Stonehenge, and such like structures; and acquaint me in what Publications $I$ can find an account of it. Its application to military purposes had not occurred to me, my thoughts not having any particular tendency that way; for a like reason it is not impossible, although perhaps not very probable, that you may not have contemplated its applicability to the Pyramids and Stonehenge. The elucidation of a difficulty that has puzzled the world for more than two thousand years is worthy of some credit; and I should be glad to acquire that to which I am fairly entitled by my discovery, if I can do so without infringing upon or appearing to usurp any share of what is due to your acknowledged priority. Had I known I was anticipated, I should have saved a good deal of time and trouble, and been spared some little expense and mortification.

The British Association meet at York next week, on the 26th instant, I believe; consequently, the sooner you favour me with a reply the more you will oblige,

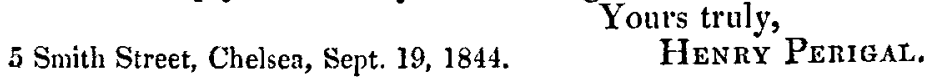

To Henry Perigal, Esq.

SiR,-I have had the pleasure to receive your favour of yesterday. In reply $I$ beg to state, that my method of raising weights has long been in practice in the artillery drills, and I do assure you that my imagination has always dwelt upon the applicability of it upon the most extended scale, from lifting a gun on to its carriage to raising a line-of-battle ship in a dock; not excluding Luxor Monoliths, Stonehenge Architraves, \&c. \&c. \&c.; and it was with reference to such general applica- 
406 Mr. Perigal on the Mode of Constructing the Pyramids.

bility, beyond the sphere of military purposes, that I mentioned it to Dr. Faraday. I wrote to him yesterday, in consequence of his having written to me upon the present occasion, and I doubt not he will have great pleasure in showing you my letter and diagram.

I trust that the time and trouble you have bestowed upon the subject may not be without their fruits; the illustrations by your diagrams will not lose their value, nor will the fact of its having slumbered a quarter of a century in the exclusive exercises of the artilleryman render less interesting the public demonstration of a principle which had been buried a hundred times as long in the Pyramids of the Ptolemies and Pharaohs.

Royal Laboratory, Woolwich, I am, Sir, yours very truly, September 21, 1844.

C. C. Dansey.

\section{Part I. Description of a Process supposed to have been adopted}

by the Egyptians to raise the Stones from step to step in the Construction of the Fyramids.

For two or three thousand years, or more, it has been a matter of wonder, and a favourite subject of surmise and inquiry, how the ancient Egyptians contrived to elevate to their places the enormous masses of stone of which the Pyramids are constructed; such being the magnitude of these structures and the supposed difficulties surmounted in their erection, that the great Pyramid was designated one of the seven " wonders of the world." What kind of engines were employed (if any were used), or what expedients were adopted to raise the ponderous stones, has continued a mystery to the present time; although various methods have been suggested, more or less practicable, not one of these conjectures has been considered a satisfactory solution of the problem which has baffled the learned and ingenious for so many ages.

Chronologers assert that the great Pyramid of Gizeh is from 4000 to 5000 years old. Herodotus, who visited Egypt about 2200 years ago, gives the following account of its erection, as described by the priests who then had charge of the Pyramids:-

"They told me likewise that Cheops, who succeeded Rhampsinitus, oppressed the Egyptians with hard labour; appointing some to receive the stones that were dug out of the quarries in the Arabian mountains and to convey them down to the Nile; and when they had been transported in vessels to the other side of that river, he appointed others to receive them, and to drag them to the mountain called the Libyan. Ten years were spent in constructing the causeway along which they drew the stones. Twenty years were spent on the $\mathrm{Py}_{\text {- }}$ ramid, which is quadrilateral, every face containing eight 
plethra* in length, and the same measure in height. All the stones $\dagger$ are 30 feet long, well-polished, and joined together with the greatest exactness. This Pyramid was built in successive layers in the form of steps, like an altar. When they had commenced in that manner they superposed other stones by means of machines consisting of short pieces of wood, raising them first from the ground to the first range; when the stone arrived there it was put on another machine, which rested on the first step, from which it was raised to the second, and so on, for the engines thus employed were equal in number to the several ranges of stones; or perhaps there was but one engine, which, being easily managed, might be removed as often as they deposited a stone; for I must mention both ways, as related to me. The summit was first completed $\$$, and the rest in succession, so that the last of all finished were the lowermost parts nearest the ground." (Herodotus, b.ii. ch. 124 and 125.)

Although the stones of the great Pyramid are not all 30 feet long, as Herodotus asserts, yet some of them are more than 40 feet long; and in the middle Pyramid of Abouseir the roof of one of the apartments is formed by three tiers of blocks, each block $48 \frac{1}{2}$ feet in length. In the ruins at Baalbec are "three stones elevated nearly 20 feet from the ground, each measuring 70 feet in length by 15 in width, while in the quarries, about a mile from the city, there still remains one enormous block, smoothed, planed, and ready for removal; it measures 70 feet in length, 14 feet in height, and is 17 feet in thickness at one end and $13 \frac{2}{3}$ feet at the other, being the same shape, but larger than those in the wall." Mr. Wood computed its weight at 2,270,000 lbs., or 1135 tons!

There appears to be no evidence to prove that the architects of the Pyramids were acquainted with any contrivances or combinations equivalent to what would be called machines or engines, according to the modern acceptation of the words; on the contrary, it seems much more probable that their gigantic undertakings were accomplished by some very simple means; which simplicity (leading to the notion that the means were self-evident) was perhaps the very reason that no record was kept, or transmitted to posterity, of their mode of operation. With this conviction, on the assumption that the statement of Herodotus might be founded on fact, I endeavoured to discover in what manner such prodigious blocks could have been elevated, from step to step, merely by the aid of short

* 808 feet.

+ Meaning, probably, the casing-stones, or polished stones with which it was faced.

$\ddagger$ Faced with polished stones. 
$408 \mathrm{Mr}$. Perigal on the Mode of Constructing the Pyramids.

pieces of roood, when the idea occurred to me that they might have been so raised by some such system as the following process:-

Each block of stone, shaped and prepared for use before it left the quarry, was conveyed across the Nile (advantage being taken of the periodical inundations) on rafts, or other appropriate vessels, to the causeway described by Herodotus; along which it was dragged on rollers, or on sledges if the stone was smoothed or polished, by the labour of men (or of cattle), to a convenient locality adjoining the Pyramid, where it remained till wanted; thence it was conducted to the first step of the Pyramid on rollers. 'To get the rollers underneath wedges were used, if it lay on the hard rock; otherwise the earth was removed from beneath one half of the stone, the director or superintendent having placed himself upon the further end to prevent it from tilting over too soon.

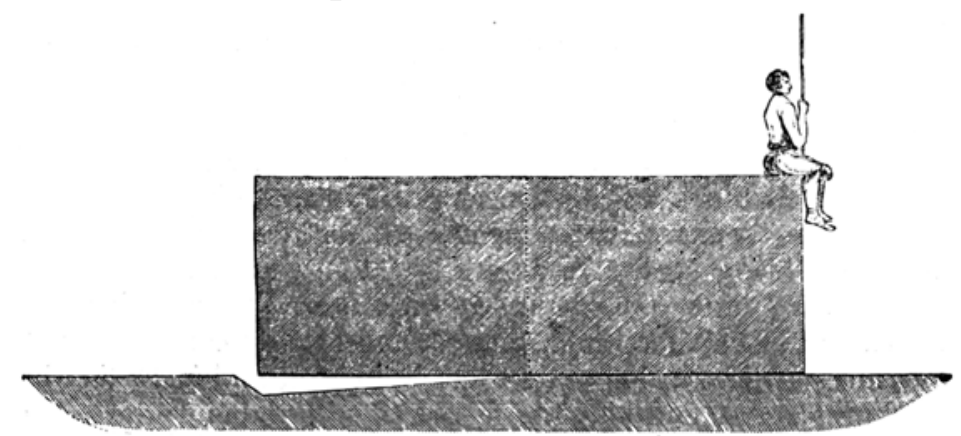

Next, the director having walked on the top to the other end, the stone (overbalanced by the leverage of his weight)

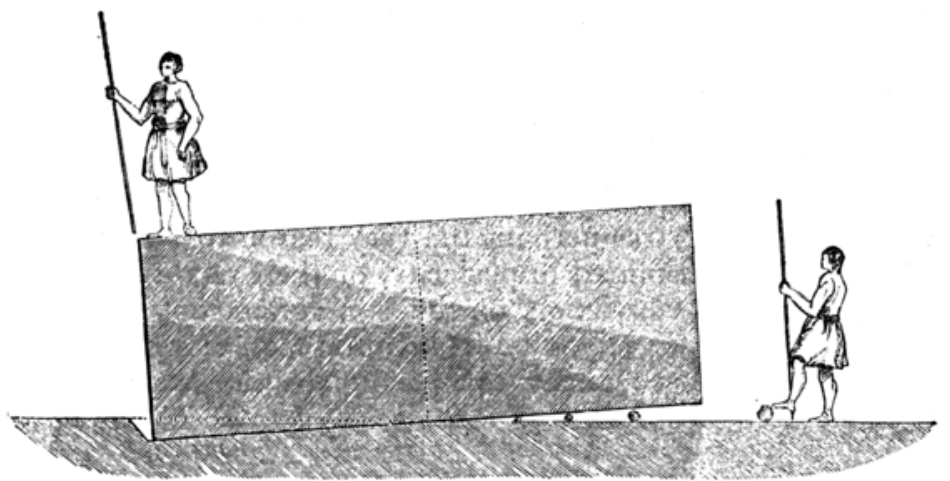

tilted into the hollow in the ground, when rollers were placed under the other half of it. 
Mr. Perigal on the Mode of Constructing the Pyramids. 409

The director having walked back again the stone was tilted on to the rollers, and conveyed to its destination at the foot of the Pyramid; where, perhaps, it was transferred in a similar way to larger rollers.

Then commenced the lifting process. All but one roller being removed, that one being as nearly as possible under the centre of gravity, the stone was tilted as before, while flat boards or planks were placed beneath; and upon these boards another very much narrower to act as a fulcrum, all being about the same length, proportioned to the width of the stone.

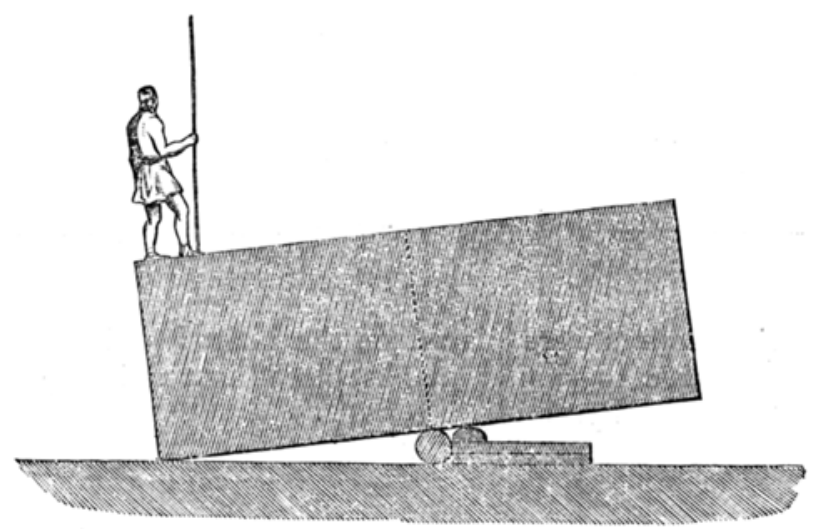

The director having walked to the other end the stone was tilted on to the boards, and similar planks were piled beneath by the side or parallel to the others, but a degree higher or more in number; and upon them also a narrow fulcrum-slip, upon which the stone was then tilted.

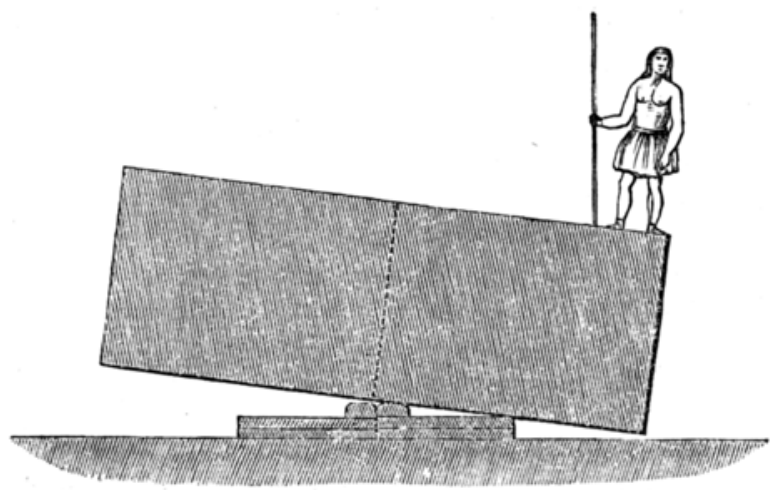

The director having repeatedly walked backwards and for- 
410 Mr. Perigal on the Mode of Constructing the Pyramids. wards, tilting each end of the stone alternately, and additional boards having been introduced every time, the stone gradually rose to the required height, rather exceeding that of the next

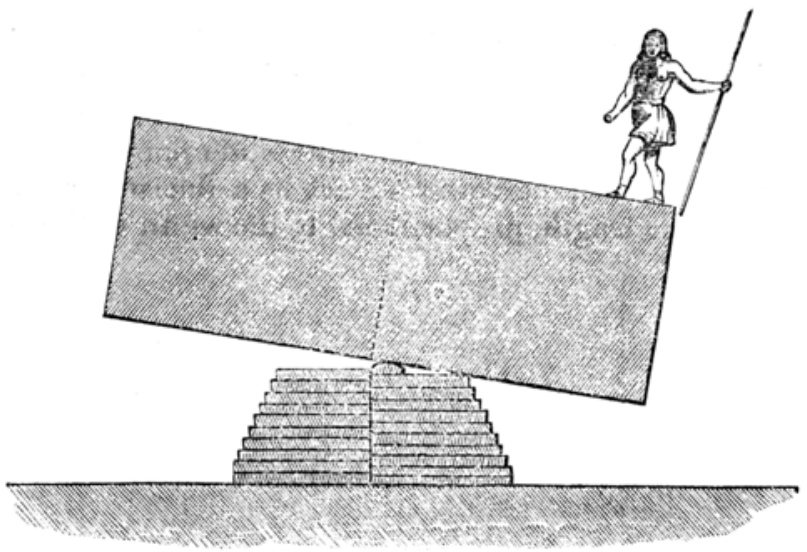

step, when rollers were placed on the boards and the stone was transferred to similar planks placed in readiness on the next step of the Pyranid.

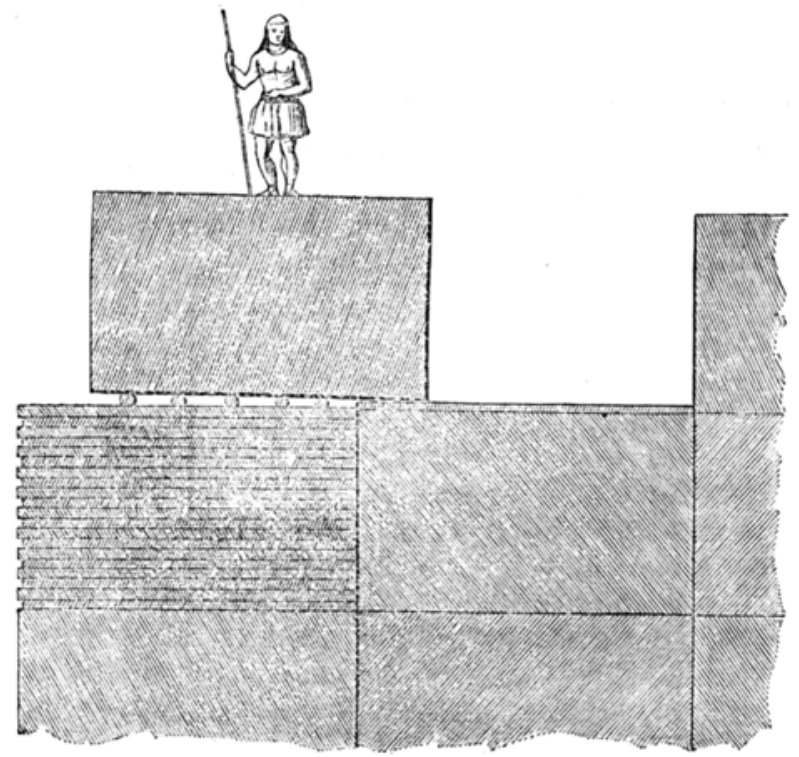

The same process was then renewed, and continued from step to step till it arrived at its destined locality. 
[N.B. In the diagrams the thickness of the planks and the consequent slope are exaggerated to make the operation more distinct and evident. The last diagram is a cross section, the others are longitudinal sections. j

Should any of the stones have been short, and consequently have afforded insufficient leverage for one man's weight to tilt them, he might have carried a load; or planks might have been made fast at the top so as to project beyond the ends of the stone for him to walk along; or two or more men might have been employed in traversing the stone; or various other expedients might, obviously, have been adopted to tilt the stone. The wood probably underwent some preparatory process by which it was condensed and its elasticity destroyed, perhaps by being subjected to very heavy pressure when sodden with boiling water.

This "the properties of the lever and of the centre of gravity were brought into co-operation, so that the reight to be lifted was itself the principal element of the lifting power." Figuratively speaking, THE STONE WAS MADE TO RAISE ITSELF BY MEANS OF ITS OWN WEIGHT.

In this manner, with the aid of a few dozen planks, a couple of men (one traversing the stone while the other arranged the planks) might have conducted to the top of the great Pyramid the largest stone used in its construction; thus corroborating the assertion of the Egyptian priests, as stated by Herodotus, that the "stones were raised from step to step lyy the aid of short pieces of rood; which, being portable and easily managed, might be removed or transferred as often as they deposited a stone; or different sets might have been employed for every range of steps." By this simple process, also, a few men might have raised Stonehenge in a single night, if the requisite stones were provided and placed in readiness near the spot, without any previous or subsequent indication of the means by which it was effected; affording the Druids a favourable opportunity of practising upon the ignorance and credulity of the multitude by ascribing its erection to supernatural agency.

In conclusion, I may add, that in looking over a good many works on Egypt and its antiquities, I have not succeeded in meeting with any direct proof that this system was the very method, or one of the methouls, actually practised by the Egyptians; but perhaps the following quotation may be interpreted into something like presumptive evidence of its probability, as the fracture of the obelisk in the middle, as there described, is an accident very likely to have occurred in the attempt to move the shaft by such a process, if the stone happened to be brittle, or its breadth and thickness too small for its length. "In one of the quarries at E'Sooan (Syene) is a granite obe- 
lisk, which, having been broken in the centre after it was finished, was left in the exact spot where it had been separated from the rock. The depth of the quarry is so small, and the entrance to it so narrow, that it was impossible for them to turn the stone in order to remove it by that opening; it is therefore evident that they must have lifted it out of the hollow in which it had been cut, as was the case with all the other shafts previously hewn in the same quarry. Such instances as these suffice to prove the wonderful mechanical knowledge of the Egyptians; and we may question whether, with the ingenuity and science of the present day, our engineers are capable of raising weights with the same facility as that ancient people." (Manners and Customs of the Ancient Egyptians, by Sir J. G. Wilkinson, F.R.S., vol. iii. p. 332.) With the latter opinion I cannot coincide; I am confident that some of our engineers could manage to construct a pyramid as large as that of Cheops, with as large stones, in a tenth part of the time, with a hundredth part of the number of workmen, if they were not limited in its cost.

Smith Street, Chelsea, September 24, 1844.

\section{On the Fish River of the Polar Sea. By Richard King, M.D.*}

FROM the period when Hearne, under the guidance of the Indian chief Motannabee, undertook his memorable journey to the Polar Sea, we have been acquainted with the source of the Thlewydezza, or Fish River. By this stream it was proposed, in 1833, to reach the wreck of the Fury, in search of Captain Sir John Ross and his party. In a short paper read before the Royal Geographical Society, and published in the third volume of its journal, the river is described, upon the authority of the Indian Blackmeat, "as being well adapted for the winter residence and support of an exploring party, both on account of its woods and the game that resorts to them; that the access to it from Great Slave Lake is easy, the water communication being interrupted by only three short portages; that the debouche is into or opposite Regent's Inlet, which points it out as well adapted for the starting-point of a boat expedition in search of the crew of any vessel known to have had the intention of visiting the wreck of the Fury." In

* Communicated by the Author; having been read before the Section of Geology and Physical Geography of the British Association, October 1, 1844, at the (second) meeting at York. On the subject of this paper see also a former communication by the author, Phil. Mag. S. 3. vol. $x x$. p. 488 . 